\title{
Assessment of Level of Development in Jawahar, Mokhada, Vikramgad and Vada Tahsil of Rural Thane District, Maharashtra State India.
}

\author{
Rajendra S. Suryawanshi \\ Associate Professor, Department of Geography, MES Abasaheb Garware College, University of Pune, \\ Pune Maharashtra, India
}

\begin{abstract}
The present research paper is an attempt to analyse the level of development in Jawahar, Mokhada, Vikramgad and Vada tahsils of rural Thane district, of Maharashtra. The research is an outcome of primary and secondary data, largely government and non government publications for preparing social and economic profile of the study area. Besides this, a topographical map is used for the physiographic profile. Further, GIS based composite Index has been prepared for all the physical, demographic, social and economic variables by denoting score of 1-5. The lowest score indicates less development and the highest score indicates high development. This has enabled to analyze the regional disparity lucidly. Based on the secondary data collection at village level, the study shows that the disparity increases from the Southwest to Northeast and majority of the settlement indicate low to very low status of development. Those administrative units that suffer in socioeconomic development i.e. lack of transport connectivity, health and low literacy levels, coupled with topographical constraints have shown low scores. These tashils are industrially backward, economically underdeveloped and socially isolated and therefore majority of the settlements of these tehsils show low level development. These tehsils are tribal dominated areas. Any developmental efforts have to be specifically focused in the deprived regions that are characterized by tribal populace, highland and socio - economic isolation.
\end{abstract}

Keywords: Regional disparity, Level of development Composite Index and GIS application.

\section{Introduction}

Diversity in India is well known fact which always hinter the planning at county level, therefore to recognize the levels of development has been a challenging task for planner. This can be at micro to macro region and even between rural and urban region. The basis of varied disparity can be physical factors coupled with economic and socio-cultural potentials and opportunities.

Thus, here an attempt has also been made to find methodologies to identify the regional development at micro level by taking a case of rural Jawahar, Mokhada, Vikramgad and Vada Tahsil of Rural Thane District, Maharashtra State India. These tahsils display widespread disparities in the levels of physical, economic and social development. In the study region, area disparities in the level of poverty, unemployment, infrastructure, mode of transport, communication, and agriculture industry and above all the level of living of the people exist significantly across the regions. The rural areas of Thane District, particularly those in the north and northeastern parts of the district stand out as the less developed areas. Though being well within reasonably short distance from the country's economic capital, Mumbai, the region has not been developed.

Some of the studies related to topic are mentioned below to understanding of regional disparities, economic disparities and economic development of the region. The research studies of Das, 2002; Dholakia, 2003; Bhattacharya and Sakthivel, 2004 have been reviewed. Wishlade and Douglas Y. (1997) have described and explained the types of disparities i.e. physical disparities, economic disparities and social disparities. They also mentioned about the regional disparity indicators and determinants of disparity in the European countries. Nidagundi (2007) has studied the regional disparities of Gulbarga division with considering urban population ratio, rural urban ration, urban growth rate, average sizes of urban centers, urban density, connectivity, accessibility and urban concentration. Suryawanshi and Sawant (2011) have studied the regional disparities of Thane District. (2013) micro level detailing of Talasari and Dahanu tehsils of Thane district. Ziari (2006) also computed the level of development of Iran based on natural index, socio-economic index and composite index. Considering the regional disparities in Iran, he has suggested the proposed plan for the development of the region.

\section{The Study Area}

The Thane district of Maharashtra State consists of 15 tahsil. The tahsil of Jawahar, Mokhada, Vikramgad and Vada is located on the Northern part of the district. The geographical area of Jawhar 640.5 
sq.km, Mokhada 492 sq.km Vikramgad 547sq.km and Vada is 775.8 sq.km (Census-2001). The density of the population in Jawhar 173, Mokhada 137, Vikramgad 209 and Vada in 184 per sq.km. The Jawhar tahsil include 107 villages and 01 town, Mokhada include 59 villages, Vikramgad include 100 villages and Vada includes 166 villages and 01towns. These tahsils are industrially backward, economically underdeveloped and socially isolated. The economic resources of the tahsils, which have potentials for the development, need to be judiciously harnessed for socio- economic empowerment of the populace of the region. (fig 1)

\section{Physical Setting}

The study area spreads over westward slope of the Western Ghats. The entire region displays characteristic undulating topography. The general slope of the region is a westward i.e. towards the Arabian sea. The Western Ghats that separates the Konkan region from the plateau runs roughly parallel to the coast. It is characterised by smooth rolling topography and highest elevated area observed over eastern part of Mokhada tehsil having more than $1100 \mathrm{~m}$.

The major rivers in study area are Surya, Lendi, Daskad, Dhamni, Domihiba, Jawahar, Shenkari, Deharji(Jawhar Tahsil), Vaitarna, Dhamni, Wagh, Pinjai, Pinjal,Gargai, Dev (Mokhada Tahasil), Deharji, Sury, Jamdari, Gaughar, Kontara (Vikramgad Tahsil), Vaitarna, Tansa Murbi, Mokhai, Muramba, Ghargai, Pinjal (Vada Tahsil) (Map). There are a few major water supply and irrigation projects in the study area for example north western part of study area Surya Project on Surya River.

Vada and Jawhar are the towns within the study area. However, in rural tracts of the district, particularly area occupied by the tribal population, life is lagging behind at least by few centuries. The rugged topography, inaccessible nature and sociological isololation of tribal people have been the factors responsible for this state. (fig 2)

\section{Objective}

The aim of the research is to find identify the level of development and then prepare composite matrices for Jawahar, Mokhada, Vikramgad and Vada in rural Thane.

\section{Data base and Methodology}

The research is purely an outcome of secondary data mainly largely government and non government publications. Census data (Village directory) has been used for preparing social and economic profile of the Jawahar, Mokhada, Vikramgad and Vada. Besides these, many reports and government publications viz. Gazetteer, Socio-economic Abstracts, periodicals have been also extensively used. Topographical maps 46H/4 ,46/H/ 8, 47/ E/ 3, 47A/13 47/E/1 47/E/5, 47/A/14, 47/E/2,47/E/6 at the scale 1:50000 have been used to evaluate the physiographic conditions and the variables such as elevation (contours), drainage, forest land, village locations, roads, railways, schools, health centres etc.

These attributes have been digitised using Auto-Cad software and subsequent GIS platform used. FCCs of the region and the LISS III digital data have been employed in identifying the actual coverage of natural vegetation. The elevation data available in raster format from ASTER GDEM DATA (data with $30 \mathrm{~m}$ ground resolution) for visual representations of selected areas. The data has been analysed at village level for all the variables of development.

\section{Indicators of Level of Development}

The following indicators have been chosen:

Physical factors: (a) Relative relief and Slope (b) Rainfall and Drainage Density (c) Forest Cover. Demographic factors: (a) Proportion of Tribal Population to total population (b) Density (c) Sex Ratio (d) Literacy

Social factors: (a) Education (b) Health (c) Transport \& Communication. (Road Density Network)

Economic factors: (a) Income (b) Non Agriculture workers (c) Banking \& Finance (Commercial Bank Facility) The composite Index has been prepared for all the physical, demographic, social and economic variables by denoting score of 1-5. (i.e. low to high) Based on the variable supporting socio-economic development of the population, the lowest score indicates less development and highest score indicates high development. This has enabled the to analyze the regional disparity lucidly (Suryawanshi and Sawant, 2013).

\section{Discussion:}

The fact that the rural Jawahar, Mokhada, Vikramgad and Vada are underdeveloped is obvious. However, it was thought appropriate to assess the developmental levels and find the degree of disparities in the level of development within Jawahar, Mokhada, Vikramgad and Vada 


\section{a) Physiographic Composite Index}

The calculated composite index of physical indicators clearly shows that the disparity increases from the West to East. The scores of composite index signify inverse relationship. Higher is the score, lesser is the disparity. Therefore, the coastal areas with composite scores more than 10 signify low physiographic composite index and it proportionally increases towards the hilly interior highlands along the longitudinal east. Ruggedness in the topography, heavy rainfall and high drainage density is the physiographic characteristic of the Eastern part of the study which comes under the Sahyadri Ghat region showing low composite score and as discussed earlier, the plains with certain advantage show high composite index clearly signifying the disparity. Very low composite index for physiographic factors are observed over 119 villages for example Karanje, Kurle (Vada); Suryamal (Mokhada); Ganeshnag, Shrirampu (Jawahar); Ambivali, Shil (Vikramgad) where as very high composite index for physiographic factors are observed over 30 villages for example Nandani, Mangrul (Vada); Karegoan, Karol (Mokhada); Khinse, Aptale (Jawahar); Baste, Khand (Vikramgad), (Fig 3)

\section{b) Demographic composite Index}

The demographic composite Index clearly reveals distinct zones of highly developed, $(>15)$, moderately developed (10-15) and less developed (3-9).Vada Tahsil falls in the Southern portions of study area having favorable demographic factors i.e. higher levels of literacy, less proportionate of S.T and favorable gender ratio show higher demographic development (viz. Biloshi, Chikhale Villege). Tahsils viz. Jawahar, Mokhada, and Vikramgad are classified as demographically less developed regions as they are characterised by dominance of tribal population, low literacy rate and unfavourable gender ratio (viz Dabheri, Palsunde and Sawade villages respectively). Southern portion of Vikramgad is the tahsil of moderate development within the Tahsil almost 50 percent villages comes under the moderate category for example Moho BK, Rampur Village. (fig 4)

\section{c) Social composite Index}

Social composite index measured through health services, road length and educational facilities show high polarization of high level of development (score >13) in and around the peripheral areas of Tahsil headquarters of Jawhar and Vada where as in case of Mokhada, having only two villages with high score i.e. Vashind and Brahmagao. In Vikramgad Tahsil four rural villages shows high social composite index which are not concentrated around the Tahsil head quarter for ex. Karhe and Shil. However, there are few pockets sporadically spread over the region. As discussed earlier, the facilities need to be increase as larger parts of selected tahsil where the scores are average to very low social composite Index $(<8)$. (fig 5$)$

\section{d) Economic Composite Index}

The synoptic view of the study region shows that there is large disparity in economic development of the region. The level of economic development decreases away from the National Highway to interior. Expecting a few pocket scattered all over the region which are basically associated with the weekly market areas for example Mokhada, Khodala, Vikramgad, the whole of the region along the Highways shows high economic development. The process of industrialisation and urbanisation has positively spelled over in the rural areas of Vada due to vicinity of Bhvandi and Vasi urban areas which are not covered in our study. Dismally, the backward tahsils i.e. Mokhada, Jawhar and Vikramgad show economic growth (CI 2 - 3). The retarding factors are agrarian economy, largely tribal population and low income/revenue (fig 6).

\section{e) Composite Index for Level of Development Status}

Here the attempt has been made to show overall level of development and disparity in four tahsils of Thane district by taking aggregate scores of Physical, Social, Economic \& Demographic aspects.

As discussed earlier, each factor was discussed with reference to composite indices and according levels of development were shown. In this section an aggregate of all the indices has been attempted. The scores range from 29 to 57. On the basis of the scores five categories for level of development status are identified. These are as follows 1) very low $(<36), 2)$ low (37-39), 3) Moderate (40-42), 4) high (43-45) and 5) very high $(>46)$. Based on this, southern zone of Vikramgad and Vada, shadow zone of Mumbai Metropolitan region i.e. entire of Bhiwandi and Sahapur stand out as the highly developed regions and precisely along the major roads and certain factors that have favored the growth is the accessibility, topography, infrastructural facilities, and positive demographic indicators. This zone shows positive indicators i.e. high accessibility, lowlands, higher percentage of proportion of population in non-agricultural activities for example Malonda, Sarshi, Ainshet, Gandhare villages from Vada Tahsil and Savaroli, Moho Kh, Zadapoli villages from Vikramgad (fig 7). and Table-1 
Table 1: Developmental Status

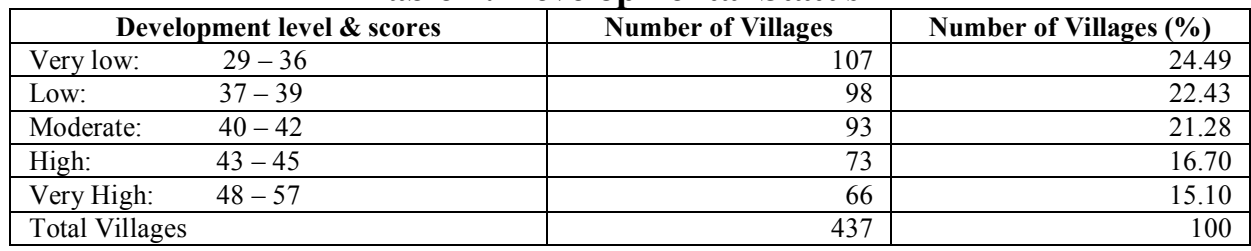

Moderately developed zone is marked away from major roads as well as far away from the district head quarters in the northern and eastern part of study area and certain factors that have favored the growth is the accessibility, topography, infrastructural facilities, and positive demographic indicators due to weekly market area and influence of surrounding developed region. Some of the representative villages fall in this category are Kelthan \& Abitghar (Vada), Kurze \& Sakhare (Vikramgad), Sawarde \& Lakshimin (Mokhada), Chauk \& Devgaon (Jawhar).

The regions showing low or very low development are seen located in the north part of Vikramgad, except central part of Jawhar, north eastern and southern parts of the Mokhada tahsil. Barring the villages along the major roads, Large number of villages fall in this category. Those administrative units that suffer in socioeconomic development i.e. lack of transport connectivity, health and low literacy levels among tribal population which is highly concentrated in this region, coupled with topographical constraints show low scores. Kalambhai, Nashera, Kunj and Pimalgao these are some representative villages comes under this category belongs to Vada, Mokhada Vikramgad and Jawhar tahsils respectively.

\section{Conclusion}

Vada tehsil and Southern part of Vikramgad tehsil of selected study tehsil are an example of contrasting regional development. This portion of study area comes under the influence of Kalyan, Bhiwandi and Vasai form industrially advanced and urbanized region of the State of Maharashtra. On the contrary, Northern part of Vikramgad, except central part of Jawhar Tahsil and most of the Mokhada Tahsil with maximum are industrially backward, economically underdeveloped and socially isolated. The deprivation of development is not only due to ruggedness of topography but also due to limited population and low demand ; whereas the plains have developed due to their natural and cultural advantage. Therefore any developmental efforts have to be specifically focused in the deprived regions that are characterized by tribal populace, highland and socio - economic isolation.

Secondly, statistical and cultural base for planning has been weak and therefore it is essential to have a concrete data base to formulate specific action plan. Different sub-regions of study area are endowed with resources- natural, social and cultural that need to be assessed and harnessed for regional development. This area specific development plan holds special importance to economically less developed and socially marginalized groups, like the tribals of study area. They have not made headway and are waiting on the edge to receive attention for development. Grass root planning with broad base and perspective would pay rich dividends in future.

Thus, the need is to develop strategies that could cater the most depressed region for balanced development. Therefore, in the planning process, government needs to adopt holistic approach, that would be transparent, decentralised and based on people's participatory.

\section{References}

[1]. Bhattacharya, B.B. and Sakthivel ,S., 2004. Regional Growth and Disparity in India. Economic and Political Weekly, (EPW), March 6, Pp.1071-1077.

[2]. Bokare, N, 1995. The Art Mart: Commercialization of Tribal Arts. In: Jain .N. and Tribhuwan R.; (Eds.), An Overview of Tribal Research Studies, Tribal Research and Training Institute Maharashtra State, Pune. Pp. 109-113.

[3]. Census of India, 1991. District Census handbook: Thane, Part XII -A and B, Series -14,Maharashtra, Government Central Press, Mumbai.

[4]. Census of India, 2001. District Census CD-ROM: Thane, Directorate of Census Operation,Govt. of Maharashtra. Mumbai.

[5]. Das, T.K., 2002. Convergence Across Indian States: Cross-Sectional and Panel Estimations. South Asia Economic Journal, Vol. 3, No. 2, Pp. 227- 239.

[6]. Dholakia, R.H, 2003. Regional Disparity in Economic and Human Development in India. RBI Chair Lecture, IIM, Ahmedabad.

[7]. Gazetteer, 2000. Gazetteer of the Bombay Presidency, Thane Places of Interest, Vol. XIV, Government Central Press, Mumbai.

[8]. Government of India, 2000. Small Scale Industries Report, The Industrial Potentials Survey of Thane District, Development Commissioner (SSI), Ministry of SSI, Agro and Rural Industries.(Accessed at- http://www.smallindustryindia.com/ publications/traderep/thane.htm)

[9]. Government of India, 2007. Maharashtra Development Report, Planning Commission. Academic Foundation, New Delhi.

[10]. Government of Maharashtra, 1982. Maharashtra State Gazetteers: Thane District. Gazetteers Department, Government of Maharashtra, Bombay.

[11]. Government of Maharashtra, 1994.General Economic Service, Annual plan Report :(1992-93). Department of Planning.

[12]. Government of Maharashtra, 2005. District socio-economic survey report: 2003-04. Directorate of evaluation and statistics, Regional Office, Konkan Bhavan, Thane. 
[13]. Government of Maharashtra, 2007. District socio-economic survey report: 2005-06, Directorate of evaluation and statistics, Regional Office, Konkan Bhavan, Thane.

[14]. Misra S. and Rao P., 1976. Regional Development Planning in India: A New Strategy. Vikas Publishing House Pvt. Ltd, Delhi. Pp. -205-214.Nair, K.R.G, 1982. Regional Experience in a Developing Economy. Wiley-Eastern, New Delhi.

[15]. Nidagundi, S.R., 2007. Regional Disparities in Urbanization of Gulburga Division in Karnataka State. The Deccan Geographer, Pune. Vol. 45, No. 1 Pp.83-97.Shaban, A., 2002. Growth and Disparities of Incomes Across States, Man and Development, September, Pp. 31-47.

[16]. Suryawanshi R.S., 2009. "Tourism Potential of Thane District": A Geographical Enquiry. Unpublished Ph,D thesis University of Pune.

[17]. Suryawanshi R.S. and Sawant N.N., 2011. Regional Disparity in Rural Thane District, Maharashtra: An Overview, Transaction Institute Indian Geographers, Vol.33No.2,PP217-230.

[18]. Suryawanshi R.S. and Sawant N.N., 2013. Assessment of Regional Disparity at Micro Level : A Study of Talasari and Dahanu Tahsils of Rural Thane, Maharashtra. Indian Journal of Spatial Science Vol.4 No.1 Summer Issue PP.28-34

[19]. Wishlade, F. and Douglas, Y., 1997. Measuring Disparities For Area Designation Purposes: Issues foe the European Union European Policies Research Centre, Glasgow. G40LT United Kingdom. Pp. 01-32.

[20]. Ziari, K., 2006. A Geographical Study of Regional Disparity in Iran, The Deccan Geographer, Pune. Vol. 44, No.1 Pp.01-15.
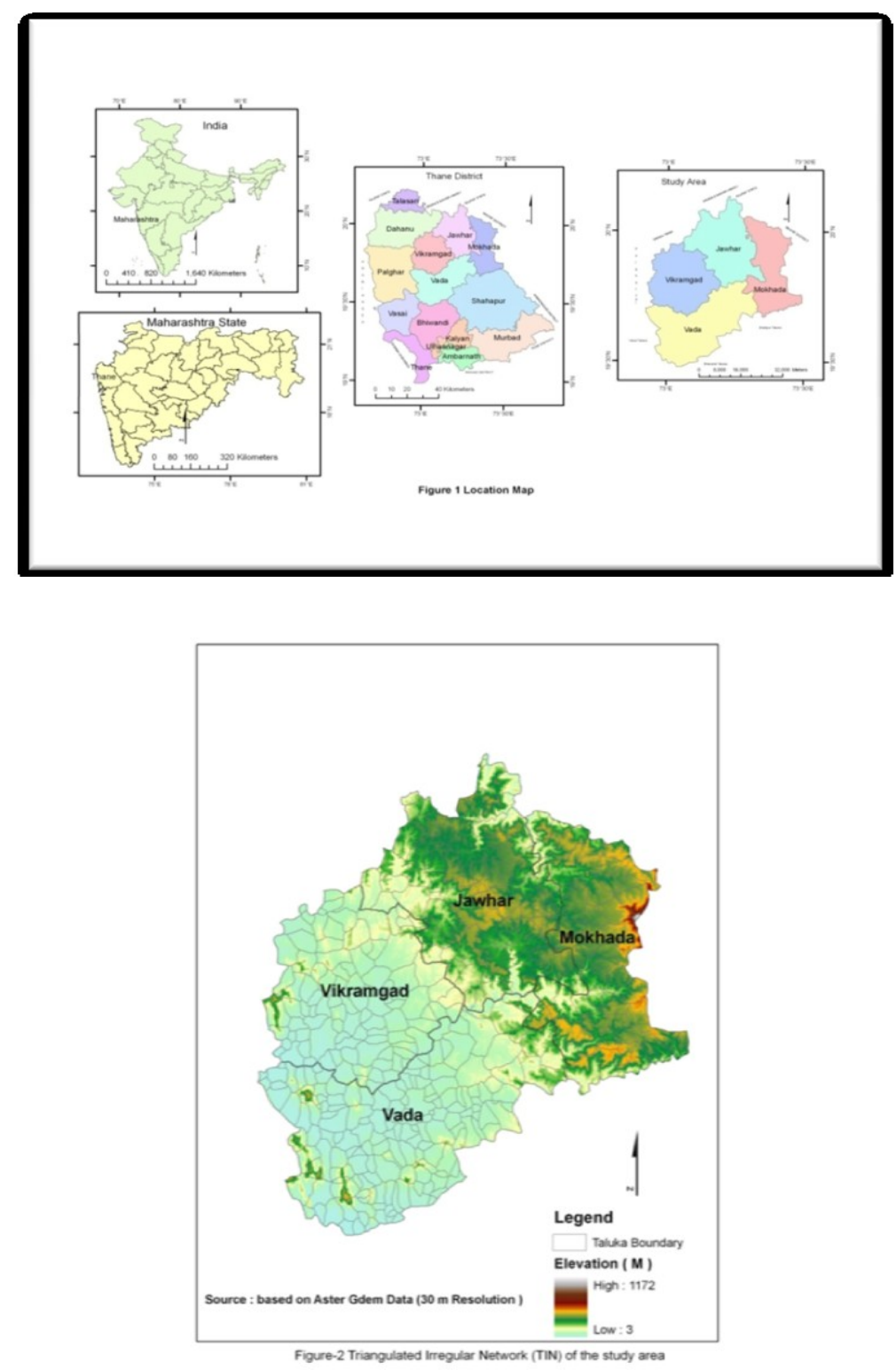

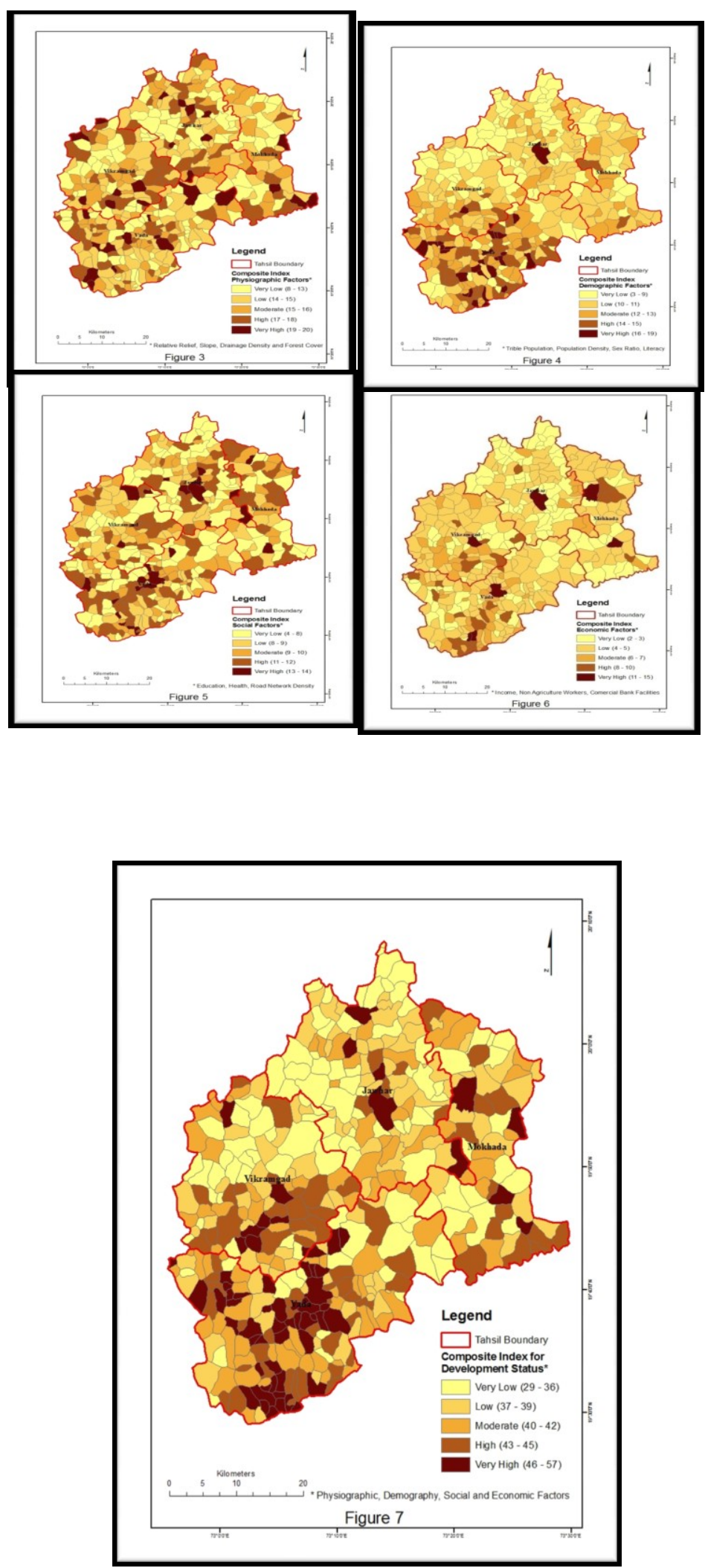